\title{
High Blood Pressure
}

causative relationship is suggested by the findings of Efrain Reisin and his colleagues who showed that even if salt intake is kept constant, overweight hypertensive subjects who diet successfully have significant reductions in blood pressure. ${ }^{5}$ More specifically, Pirjo Pietinen and fellow workers undertook a comprehensive review of studies relating animal fat intake to blood pressure elevation. It was found that in populations as disparate as those of Finland and the United States there was a positive relationship between a diet high in saturated and low in polyunsaturated fat on the one hand and blood pressure levels on the other. ${ }^{6}$ Conversely, other studies reviewed by these authors showed that increasing the $\mathrm{P} / \mathrm{S}$ ratio was followed by a fall in blood pressure even if the total fat intake remained the same. The decline in systolic blood pressure ranged from 1 to $13 \mathrm{mmHg}$ and up to $8 \mathrm{mmHg}$ in the case of the diastolic. Switchback observations with reduction in $\mathrm{P} / \mathrm{S}$ ratio were made in nine studies. In seven they resulted in an increase in systolic and diastolic pressures when the ratio was low. The findings of $\mathrm{J} \mathbf{M}$ Iacono and co-workers were confirmatory. They found that a six-week reduction in dietary fat content from 42 to 25 per cent with an increase in the polyunsaturated-saturated ratio resulted in a reduction in both the systolic and the diastolic pressures of normotensive healthy adult volunteers. The total energy intake was unchanged during the observation period. ${ }^{8}$ Quantitatively, linoleic acid was the commonest polyunsaturated fatty acid in these diets. In experimental rats its administration has been found to have a diuretic effect, increasing sodium excretion, a precursor of blood pressure fall. ${ }^{9}$ In contrast, Pietinen and colleagues have reported animal studies indicating that diets deficient in linoleic acid are associated with blood pressure elevation. ${ }^{10}$ In combination these observations indicate a linkage of hypertension with diets conducive to obesity and either high in saturated or low in unsaturated fats.

\section{Fibre}

The evidence for a decline in consumption of fibre by the middle and upper classes during the course of the eighteenth century was presented in Chapter V. A considerable body of evidence is indicative of an inverse relationship between fibre intake and blood pressure levels. Angela Wright and her colleagues compared the blood pressures of ninety-four subjects taking experimental diets that were consistently either high or low in fibre. At the end of four weeks the mean systolic and diastolic pressures

\footnotetext{
${ }^{5}$ Efrain Reisin et al., 'Effect of weight loss without salt restriction on the reduction of blood pressure in overweight hypertensive patients', $N$ Engl J Med, 1978, 298: 1-6, pp. 2-4. p. 11.

${ }^{6}$ Pirjo Pietinen et al., 'Dietary fat and blood pressure-a review', Eur Heart J, 1987, 8: Suppl B 9-17,

${ }^{7}$ Ibid., p. 12.

${ }^{8} \mathrm{~J}$ M Iacono et al., 'Reduction in blood pressure associated with high polyunsaturated fat diets that reduce blood cholesterol in man', Prev Med, 1975, 4: 426-43, p. 443.

${ }^{9} \mathrm{~J}$ Rosenthal, P G Simone and A Silbergleit, 'Effects of prostaglandin deficiency natriuresis, diuresis and blood pressure', Prostaglandins, 1974, 5: 435-40, p. 440.

${ }^{10}$ Pietinen et al., op. cit., note 6 above, p. 13.
} 


\section{Chapter VII}

Table VII.3

Relationship between fibre intake and blood pressure

\begin{tabular}{lccc}
\hline & Number of subjects & \multicolumn{2}{c}{ Blood pressure (mmHg) } \\
\cline { 2 - 4 } & & Systolic & Diastolic \\
\hline High fibre & 45 & $116 \pm 1.5^{*}$ & $75.2 \pm 1.0^{* *}$ \\
Low fibre & 49 & $123 \pm 1.3^{*}$ & $78.5 \pm 0.8^{* *}$ \\
\hline
\end{tabular}

${ }^{*} \mathrm{P}<.001 * * \mathrm{P}<.02$

Source: Angela Wright, P G Burstyn and M J Gibney, 'Dietary fibre and blood pressure', $\mathrm{Br}$ Med J, 1979, ii: 1541-3, p. 1542. (With permission of the BMJ Publishing Group.)

were slightly but significantly higher in the low fibre group (Table VII.3). ${ }^{11}$ Their findings were subsequently confirmed in a study conducted by Lawrence Appel and his co-workers. At the end of a three week run in and eight weeks of controlled diets, volunteer subjects whose blood pressures were initially comparable diverged. The control subjects who were continued on a typical North American diet ended with mean blood pressures higher than those of the subjects whose diet was enriched in fibre. ${ }^{12}$ Together the two studies indicate that a diet lacking in fibre is conducive to blood pressure elevation, both systolic and diastolic.

\section{Salt}

Salt is the only condiment which is a physiological necessity. Concern about harmful effects of high consumption arose only in the twentieth century. Salt as a supplement had been deemed invaluable as a preservative and esteemed from the early days of recorded history. ${ }^{13}$ It was included in sacrifices in early biblical times when inviolable obligations were designated salt covenants. ${ }^{14}$ Homer considered the salt with which the meat of celebratory feasts was sprinkled to be divine. ${ }^{15}$ Its commercial importance in Roman times is attested by the designation of money given to soldiers for salt ( $\mathrm{sal}$ ) as salarium from which the word salary is derived. Until recently a person in authority visiting a community would often be offered bread and salt as a ceremonial expression of welcome and a form of homage.

In medieval and Tudor times salt was produced exclusively by evaporation of sea water in maritime basins. ${ }^{16}$ In England the climate prevented this from occurring naturally to a reliable extent as in Mediterranean countries, and evaporation depended

\footnotetext{
${ }^{11}$ Angela Wright, P G Burstyn and M J Gibney, 'Dietary fibre and blood pressure', $\mathrm{Br} \mathrm{Med} J, 1979$, ii: $1541-3$, p. 1542 .

12 Lawrence J Appel et al., 'A clinical trial of the effects of dietary patterns on blood pressure', $N$ Engl J Med, 1997, 336: 1117-24, p. 1122.

${ }^{13}$ S A M Adshead, Salt and civilization, New York, St Martin's Press, 1992, pp. 25, 27.

${ }^{14}$ Leviticus, 2:13; Numbers 18:19.

${ }^{15}$ Homer, Iliad, 9.214.

${ }^{16}$ Adshead, op. cit., note 13 above, p. 86.
} 